\title{
Polyphenolic extract of lotus root (edible rhizome of Nelumbo nucifera) alleviates hepatic steatosis in obese diabetic $d b / d b$ mice
}

Yumi Tsuruta 1,2,3, Koji Nagao ${ }^{1,2}$, Shunichi Kai ${ }^{1}$, Keisuke Tsuge ${ }^{3}$, Takashi Yoshimura ${ }^{3}$, Kazuyoshi Koganemaru ${ }^{3}$ and Teruyoshi Yanagita ${ }^{1,2^{*}}$

\begin{abstract}
Background: Nonalcoholic fatty liver disease (NAFLD) is emerging as the most common liver disease of industrialized countries. Thus, discovering food components that can ameliorate NAFLD is of interest. Lotus root, the edible rhizome of Nelumbo nucifera, contains high levels of polyphenolic compounds, and several healthpromoting properties of lotus root have been reported. In this study, we tested whether feeding a polyphenolic extract of lotus root to $d b / d b$ mice protects them from hepatic steatosis.

Results: After 3 weeks of feeding, the hepatomegaly and hepatic triglyceride accumulation were markedly alleviated in the lotus polyphenol-diet-fed $d b / d b$ mice relative to the control mice. Although the lipolytic enzyme activity was not changed, the activities of lipogenic enzymes, such as fatty acid synthase and malic enzyme, were significantly lower in the lotus polyphenol diet-fed $d b / d b$ mice. Additionally, the ESI-IT/MS and MALDI-TOF MS spectra revealed the presence of B-type proanthocyanidin polymers with polymerization degree up to 9 in the polyphenolic lotus root extract.
\end{abstract}

Conclusion: We speculate that the condensed tannins contained in lotus root can alleviate hepatic steatosis by suppressing the lipogenic enzyme activity in the livers of $d b / d b$ mice.

\section{Background}

Nonalcoholic fatty liver disease (NAFLD) is often associated with features of the metabolic syndrome and is emerging as the most common liver disease worldwide [1-4]. NAFLD is the preferred term for describing the spectrum of liver damage that ranges from hepatic steatosis to steatohepatitis, liver fibrosis, and cirrhosis. Most of the liver-related morbidity and mortality are associated with the development of cirrhosis, which is most likely to occur in individuals who have progressed from hepatic steatosis to steatohepatitis. The processes by which steatohepatitis evolves from hepatic steatosis are not fully understood; nevertheless, developing effective therapies for treating NAFLD is necessary, and discovering nutrients that can reduce the risk of NAFLD would be useful. $d b / d b$ mice suffer from hyperphagia, because

\footnotetext{
* Correspondence: yanagitt@cc.saga-u.ac.jp

${ }^{1}$ Department of Applied Biochemistry and Food Science, Saga University,

Saga 840-8502, Japan

Full list of author information is available at the end of the article
}

they have a missense mutation on the leptin receptor gene. They develop a syndrome that involves multiple metabolic and hormonal disorders, including NAFLD, and shares many features with human metabolic syndrome [5-7].

Diet has been recognized as factor that contributes to the development and prevention of NAFLD [8-11], and polyphenol-rich plants and fruits have been used in folk medicines throughout the world for treating lifestylerelated diseases [12-14]. Nelumbo nucifera is a plant in the monogeneric family Nelumbonaceae. Its rhizome (lotus root) is recognized in eastern countries as one of the most delicious and nutritional vegetables, and it has also been used in traditional Asian herbal medicine. There are several studies showing that lotus root contains high levels of polyphenolic compounds and possesses several beneficial health properties, such as hypoglycemic, anti-inflammatory and antioxidant activities [15-18]. Our previous study showed that feeding lotus root powder prevents the development of NAFLD 
in obese diabetic $d b / d b$ mice (submitted data). In the present study, we evaluated the effect of a diet supplemented with a polyphenolic extract of lotus root on the development of NAFLD in $d b / d b$ mice. Additionally, the structures of the polyphenolic lotus root extract were characterized through analyses combining a butanolic$\mathrm{HCl}$ assay, electrospray-ionization mass spectrometry (ESI/MS), and matrix-assisted laser-desorption ionization time-of-flight mass spectrometry (MALDI-TOF MS).

\section{Materials and methods Animals and diets}

All aspects of the experiment were conducted according to the guidelines provided by the ethical committee for experimental animal care of Saga University. Six-weekold male $d b / d b$ mice (C57BLKS/J Iar- + Lepr ${ }^{d b} /+L e p r^{d b}$ ) were purchased from Japan SLC (Shizuoka, Japan). The mice were housed individually in plastic cages in a temperature-controlled room $\left(24^{\circ} \mathrm{C}\right)$ under a 12 -h light/dark cycle. The basal semisynthetic diets were prepared according to the recommendations of the AIN-76 [19] (Table 1). The freeze-dried lotus root powder were provided by the Industrial Technology Center of Saga and the preparation of the polyphenolic lotus root extract was performed as shown in Figure 1. Approximately $16 \mathrm{~g}$ of polyphenolic extract was obtained from $1000 \mathrm{~g}$ of freeze-dried lotus root powder, and the extract included $892 \mathrm{mg} / \mathrm{g}[(+)$-catechin equivalent] total polyphenolic substances, as estimated by the Folin-Ciocalteu method [20]. The $d b / d b$ mice were assigned to two groups (of six mice each) that were fed one of two diets (Table 1): a semisynthetic AIN-76 diet (the control group) or a semisynthetic AIN-76 diet supplemented with 0.5\% lotus root polyphenol at the expense of sucrose (the lotus polyphenol group). The mice were pair-fed the diets for 3 weeks using the Rodent CAFE (KBT Oriental Co. Ltd., Saga, Japan). At the end of the feeding period and after a 9-h starvation period, the mice were sacrificed under

Table 1 The composition of the experimental diets

\begin{tabular}{lll}
\hline Ingredients & Control & Lotus polyphenol \\
\hline & & $\%$ \\
Casein & 20.0 & 20.0 \\
Corn starch & 15.0 & 15.0 \\
Cellulose & 5.0 & 5.0 \\
Mineral mixture (AIN 76) & 3.5 & 3.5 \\
Vitamin mixture (AIN 76) & 1.0 & 1.0 \\
DL-Methionine & 0.3 & 0.3 \\
Choline bitartrate & 0.2 & 0.2 \\
Corn oil & 5.0 & 5.0 \\
Lotus root polyphenol & - & 0.5 \\
Sucrose & 50.0 & 49.5 \\
\hline
\end{tabular}

pentobarbital sodium salt anesthesia by exsanguination from the heart. The white adipose tissue (WAT) and the livers were excised immediately, and the serum was separated from the blood.

\section{Measurement of the triglyceride and cholesterol levels in the liver}

The liver lipids were extracted according to the method of Folch et al. [21], and the concentrations of triglyceride and cholesterol were measured using the methods of Fletcher [22] and Sperry \& Webb [23], respectively.

\section{Measurement of the serum parameters}

The serum triglyceride and cholesterol levels were measured using commercial enzyme assay kits (Wako Pure Chemicals, Tokyo, Japan). The serum glutamic pyruvic transaminase (GPT) and alkaline phosphatase (ALP) activities were measured using commercial enzyme assay kits (Wako Pure Chemicals, Tokyo, Japan).

\section{Assays of the hepatic enzyme activity}

The enzyme activities of fatty acid synthase (FAS) [24] and malic enzyme [25] in the cytosomal fraction and of carnitine palmitoyltransferase (CPT) [26] in the mitochondrial fraction were determined as has been described elsewhere. The protein concentration of each fraction was determined according to the method of Lowry et al. [27], with bovine serum albumin used as the standard.

\section{Lotus root polyphenol analysis}

First, a colorimetric butanolic- $\mathrm{HCl}$ assay for procyanidins was employed to assess the polyphenolic lotus root extracts; it used procyanidinB2 as the positive standard and $(+)$-catechin as the negative standard [28]. Second, a structural analysis of the lotus root polyphenol components was conducted by direct-infusion ESI/MS. The ESI/ MS spectrometry was performed using a HCT-Ultra system (Bruker Daltnics GmbH, Bremen, Germany). The sample was dissolved in $50 \%$ methanol $(1 \mathrm{mg} / \mathrm{mL})$ and directly infused into the ESI/MS system at $0.2 \mathrm{~mL} / \mathrm{h}$ with a syringe pump. The analytical conditions of the ESI/MS were as follows: ion mode, negative; capillary voltage, $4 \mathrm{kV}$; capillary exit, -241 V; nebulizing gas, 45 psi; flow rate of dry gas, $10 \mathrm{~L} / \mathrm{min}$; dry temperature, $350^{\circ} \mathrm{C}$; an scan range, $100-3,000 \mathrm{~m} / \mathrm{z}$. Finally, a MALDI-TOF MS analysis was performed to obtain further lotus root polyphenol structural information. The MALDI-TOF MS analysis was conducted using an Autoflex III Smartbeam system (Bruker Daltnics GmbH, Bremen, Germany). The sample was dissolved in $50 \%$ methanol $(2 \mathrm{mg} / \mathrm{mL})$ and premixed with 2,5-dihydroxybenzoic acid $(20 \mathrm{mg} / \mathrm{mL}$ in $50 \%$ acetonitrile containing $0.1 \%$ trifluoroacetic acid) and sodium trifluoroacetate $(2 \mathrm{mg} / \mathrm{mL}$ in acetonitrile) at a ratio of 2:10:1. Then, $1 \mu \mathrm{L}$ of the premixed sample solution was deposited 


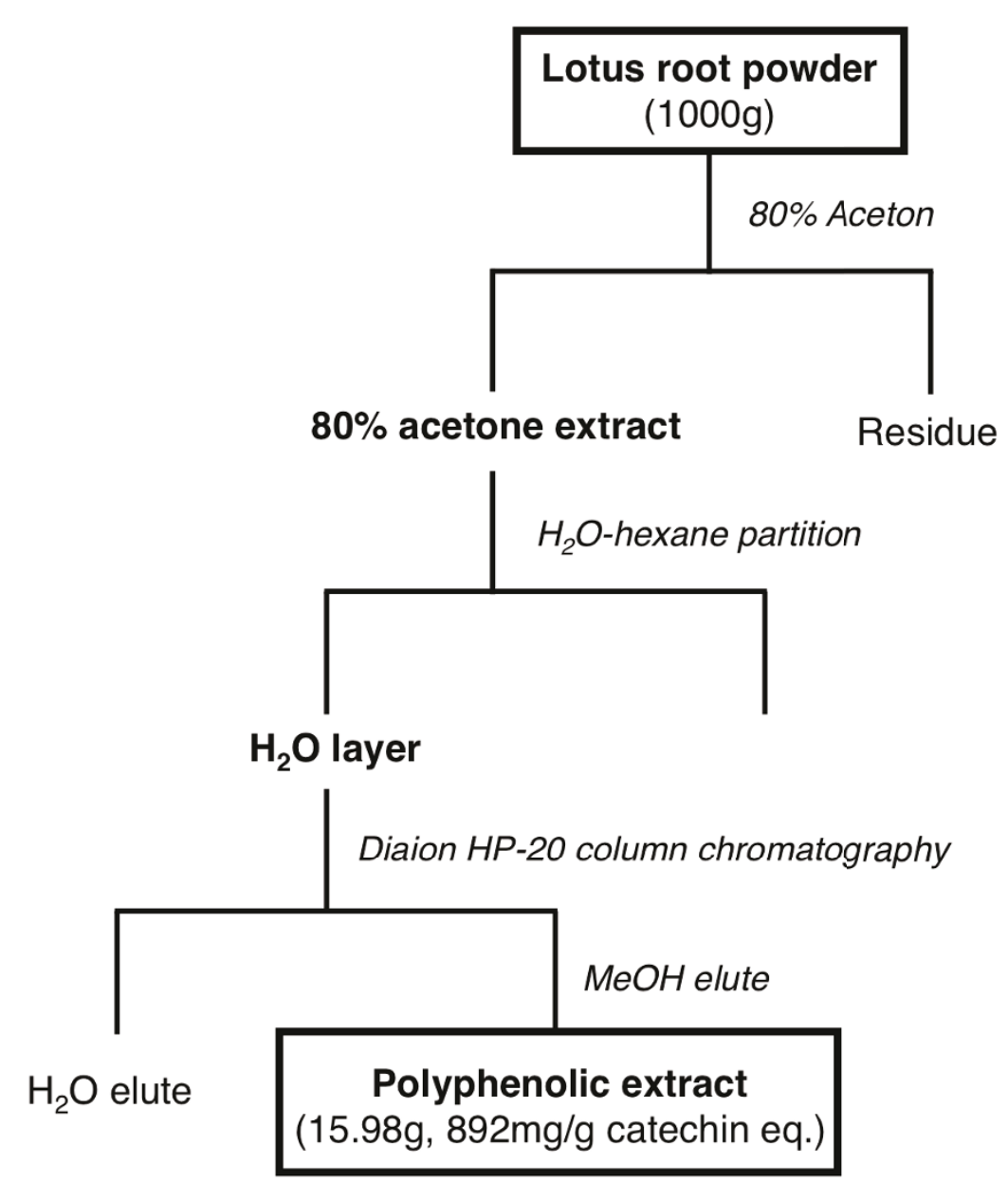

Figure 1 Preparation of the polyphenolic extracts from the lotus root powder

onto a stainless steel MALDI target plate and allowed to dry at room temperature. The analytical conditions of the MALDI-TOF MS analysis were as follows: ion mode, reflector positive; ion source 1 voltage, $19 \mathrm{kV}$; ion source 2 voltage, $16.85 \mathrm{kV}$; lens voltage, $8.7 \mathrm{kV}$; paused ion extraction, $100 \mathrm{~ns}$; and mass range, $500-3,000 \mathrm{~m} / \mathrm{z}$. The mass spectra were acquired by averaging 1,000 laser shots.

\section{Statistical analysis}

All of the values are expressed as the means \pm standard error. The significance of the differences between the means of the two groups was determined by the Student's $t$-test. Differences were considered to be significant at $p<0.05$.

\section{Results and Discussion}

NAFLD is common in type 2 diabetic and obese patients. Although the mechanisms responsible for the development of NAFLD are unclear, it has been suggested that hepatic steatosis results from increased lipogenesis and/or decreased lipolysis, in addition to the accelerated mobilization of the expanded visceral WAT fat to the liver $[2,3]$.

Effects of the lotus polyphenol diet on growth parameters in $d b / d b$ mice

The two groups of $d b / d b$ mice did not differ in their initial body weight, nor did they differ in their final body weight, food intake, or total WAT weight during and after the 3-week feeding period (Table 2). By contrast, the relative liver weight and hepatic triglyceride concentration differed between the $d b / d b$ mice fed the control and lotus polyphenol diets (Figure 2).

Effects of Lotus polyphenol diet on hepatic lipids in $d b$ / $d b$ mice

The relative liver weight was $15 \%$ less in the lotus polyphenol diet-fed $d b / d b$ mice, and this lower liver weight was associated with markedly less (62\%) triglyceride accumulation in the liver (Figure 2). However, the 
Table 2 The effect of polyphenolic lotus root extract on growth parameters in $d b / d b$ mice

\begin{tabular}{lcc}
\hline & Control & Lotus polyphenol \\
\hline Initial body weight $(\mathrm{g})$ & $33.7 \pm 0.6$ & $33.7 \pm 0.5$ \\
Final body weight $(\mathrm{g})$ & $37.4 \pm 0.6$ & $35.8 \pm 1.7$ \\
Food intake $(\mathrm{g})$ & $109 \pm 3$ & $109 \pm 1$ \\
White adipose tissue weight (g/100 g body weight) & \\
Total & $6.92 \pm 0.12$ & $6.53 \pm 0.25$ \\
$\quad$ Epididymal & $4.30 \pm 0.12$ & $4.10 \pm 0.14$ \\
$\quad$ Perirenal & $2.61 \pm 0.06$ & $2.43 \pm 0.13$ \\
\hline
\end{tabular}

The values are expressed as the mean \pm standard error for six mice.

hepatic cholesterol level was not different between the two groups (control group, $2.98 \pm 0.19 \mathrm{mg} / \mathrm{g}$ liver; lotus polyphenol group, $3.49 \pm 0.21 \mathrm{mg} / \mathrm{g}$ liver).

Effects of the lotus polyphenol diet on serum parameters in $d b / d b$ mice

The serum cholesterol levels and triglyceride levels were not different between the two groups (Table 3). Consistent with alleviation of the hepatomegaly and hepatic steatosis by the lotus polyphenol diet, the activities of hepatic injury markers, such as GPT and ALP, tended to be lower (by $24 \%$ and $17 \%$, respectively) in the sera of the lotus polyphenol diet-fed $d b / d b$ mice than in the sera of the control diet-fed $d b / d b$ mice (Table 3). These results suggest that the polyphenolic lotus root extract can prevent the development of NAFLD in the $d b / d b$ mice.

Effects of the lotus polyphenol diet on enzyme activity related to lipid metabolism in the livers of $d b / d b$ mice To further examine the effect of the lotus polyphenol diet on the liver, the hepatic enzymes related to
Table 3 The effect of polyphenolic lotus root extract on serum parameters in $d b / d b$ mice.

\begin{tabular}{lll}
\hline & Control & Lotus polyphenol \\
\hline Triglyceride (mg/dL) & $99.8 \pm 9.1$ & $106 \pm 14$ \\
Cholesterol (mg/dL) & $166 \pm 15$ & $182 \pm 10$ \\
ALP (IU/L) & $40.3 \pm 5.5$ & $30.7 \pm 2.9$ \\
GPT (IU/L) & $110 \pm 17$ & $91.5 \pm 4.6$ \\
\hline
\end{tabular}

The values are expressed as the mean \pm standard error for six mice. GPT, glutamic pyruvic transaminase; ALP, alkaline phosphatase.

triglyceride metabolism were analyzed (Figure 3 ). Although the activity of CPT (a key enzyme in fatty acid $\beta$-oxidation) was not changed, the activities of FAS and malic enzyme (lipogenic enzymes related to de novo fatty acid biosynthesis) were significantly lower in the lotus polyphenol diet-fed $d b / d b$ mice. Previous studies have demonstrated that dietary polyphenols suppress lipogenesis. Previous reports have indicated that polyphenols from plants have FAS inhibitory activity in vitro [29], and we have reported that feeding tea catechins (which are rich in (-)-epigallocatechin gallate and (-)-epicatechin gallate) to rats results in reduced visceral fat deposition through a reduction of hepatic FAS activity [30]. Given that the lotus root powder in our previous study also suppressed hepatic FAS activity, we speculate that the ameliorative effect of lotus root on hepatic steatosis in $d b / d b$ mice is partly attributable to the suppression of hepatic lipogenic enzyme activity by the lotus root polyphenols.

Lotus root polyphenol analysis

The colorimetric butanoic- $\mathrm{HCl}$ assay showed that the polyphenolic lotus root extract contained proanthocyanidins

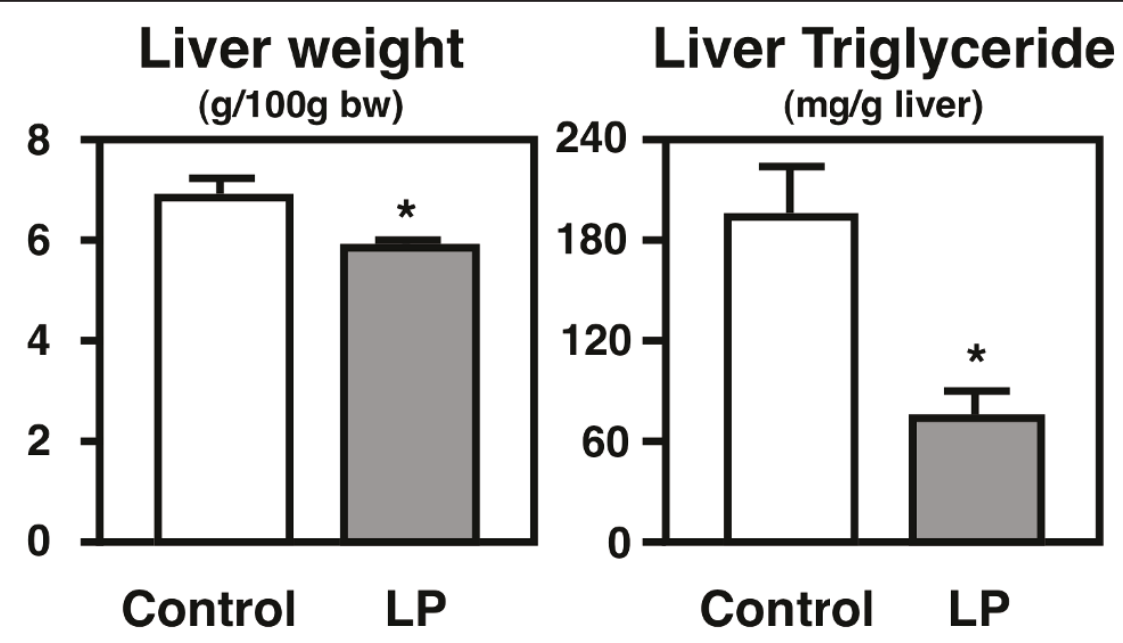

Figure 2 The relative liver weights and hepatic triglyceride levels in the $d b / d b$ mice. The mice were fed the control diet or the lotus root polyphenol diet for 3 weeks. The values are expressed as the mean \pm standard error for six mice. See Table 1 for the composition of the diets. ${ }^{*}$ Significant $(P<0.05)$ difference between the control and lotus polyphenol groups of $d b / d b$ mice. 


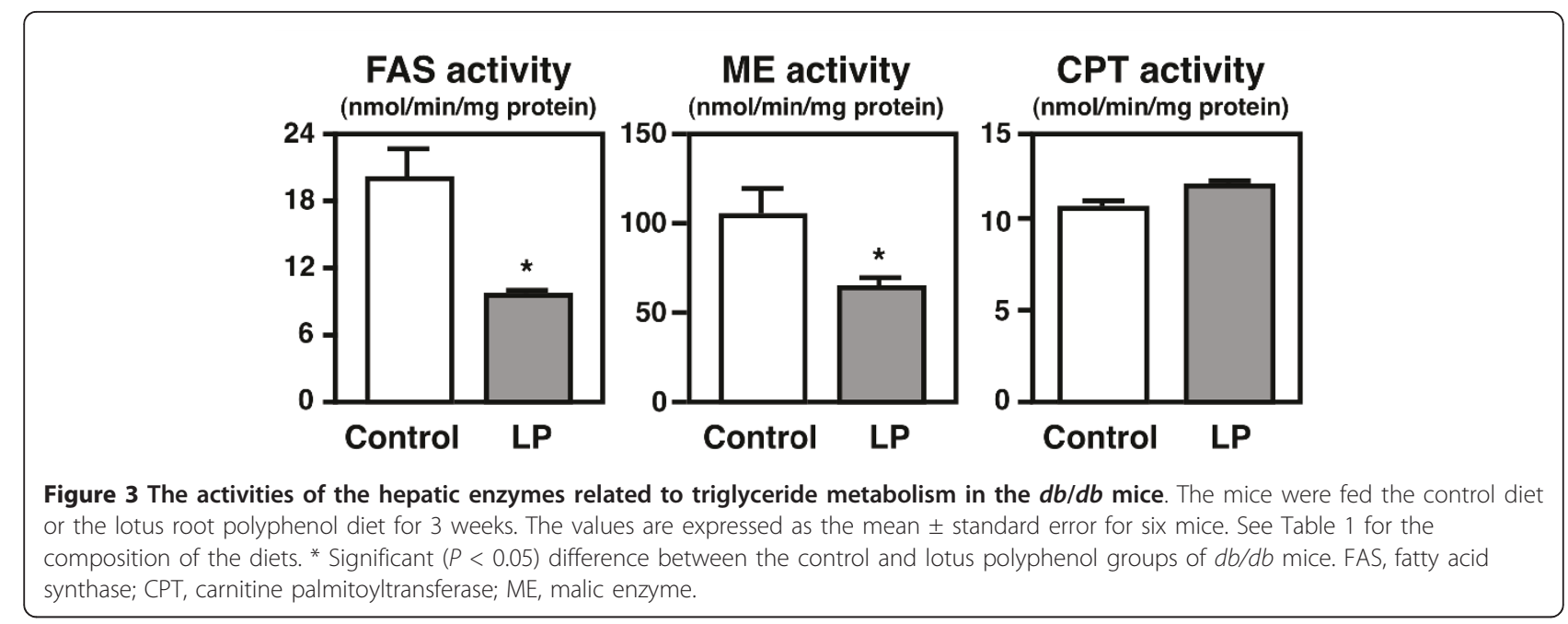

(Figure 4). The lotus root polyphenols were further characterized by ESI/MS and MALDI-TOF MS spectrometry. The ESI/MS spectra were recorded in the negative ion mode, which detects proanthocyanidin molecules better detected than the positive ion mode, and they showed the existence of epi/catechin, epi/gallocatechin, and B-type proanthocyanidins (Figure 5). The degree of polymerization of proanthocyanidin was calculated by the formula of Btype proanthocyanidin mass calculation. Additionally, both procyanidin (polymeric tannins composed of catechin) and prodelphinidin (polymeric tannins composed of gallocatechin) homopolymers and as a complex series of procyanidin-prodelphinidin heteropolymers with polymerization degree up to 9 were detected through the MALDI-TOF MS analysis (Figure 6). The putative structure of the condensed tannins in the polyphenolic lotus root extract is illustrated in Figure 7. There are several studies reporting that proanthocyanidins possess various in vivo physiological properties, such as antioxidant, anti-carcinogenesis, and anti-inflammatory activities [31-33]. Additionally, previous reports have indicated that dietary proanthocyanidins have hypolipidemic properties and that proanthocyanidins from grape seed and persimmon peel down-regulate the expression of lipogenic genes by reducing the steroid response element binding protein 1 transcription factor [34-36]. Deprez et al. have shown that proanothocyanidin dimmers and trimmers have similar permeability coefficients in Caco-2 cells [37], and absorption of dimeric and trimeric procyanidins has been demonstrated in rat and human sera [38-40]. Further investigation in future studies will be

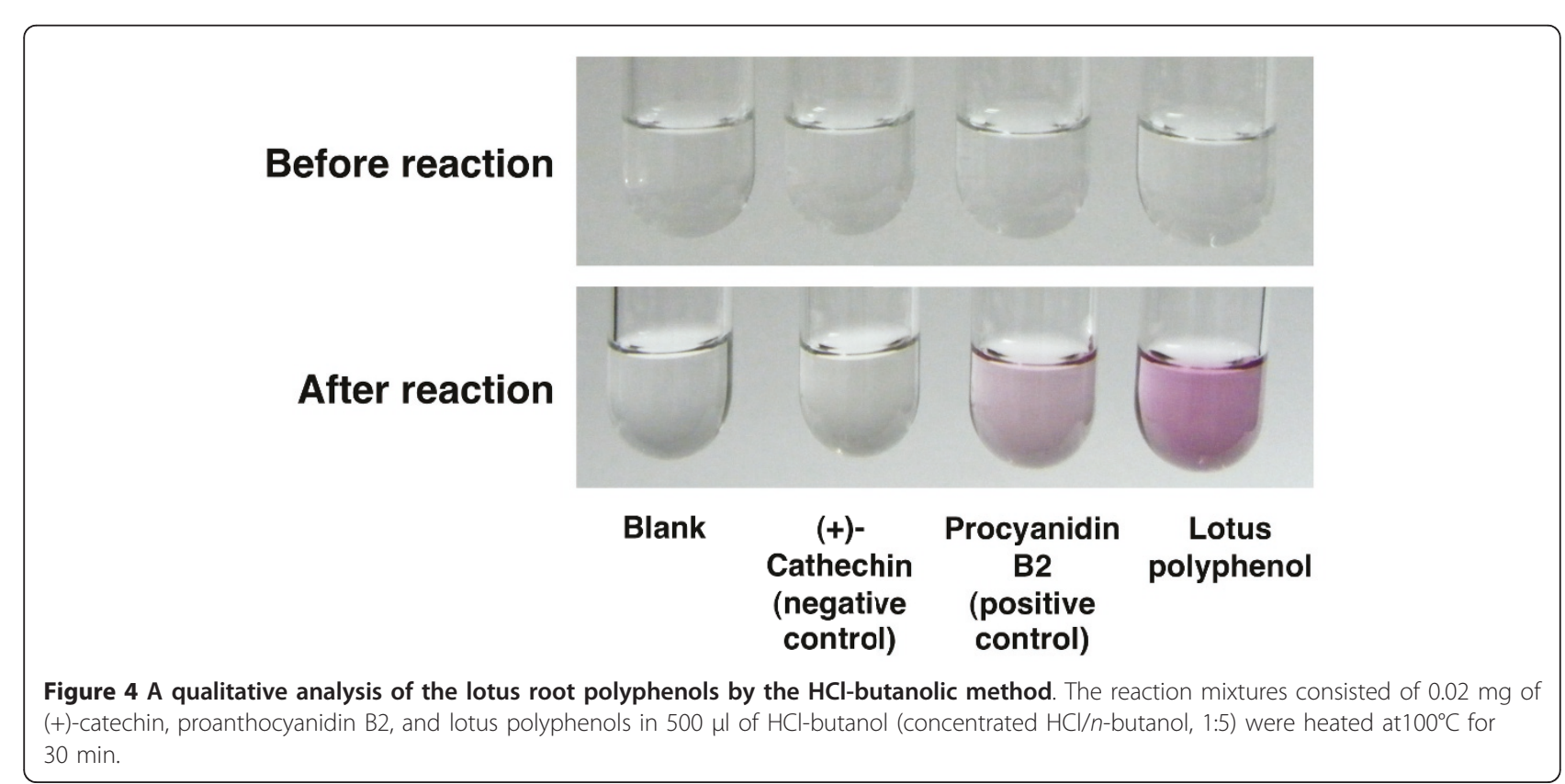




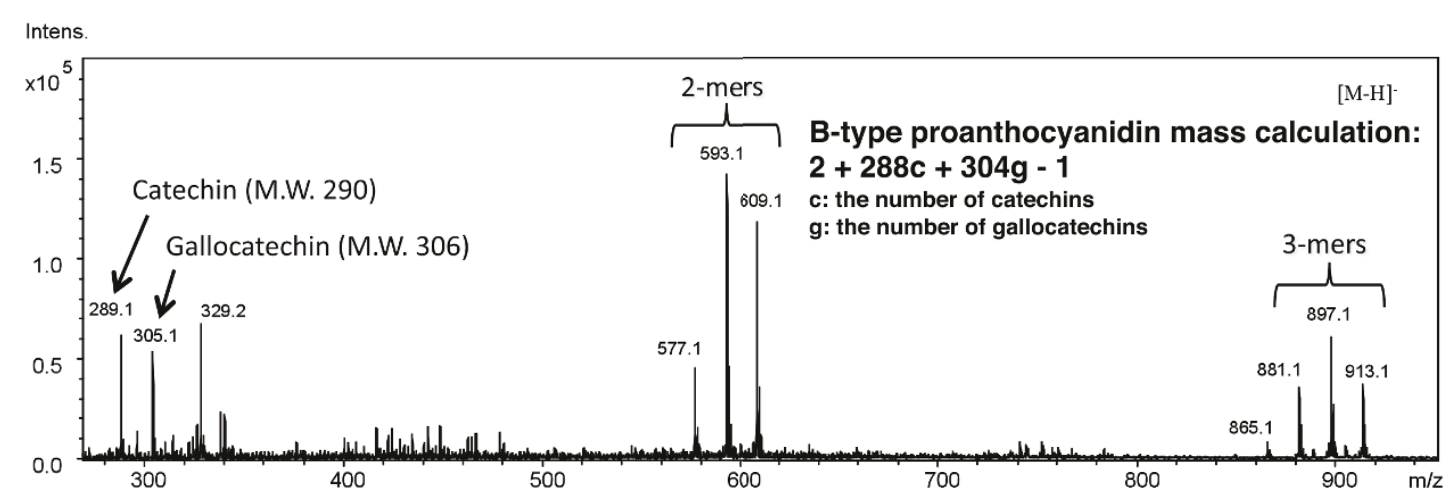

Figure 5 The negative ion mode ESI/MS spectra of the lotus root polyphenols

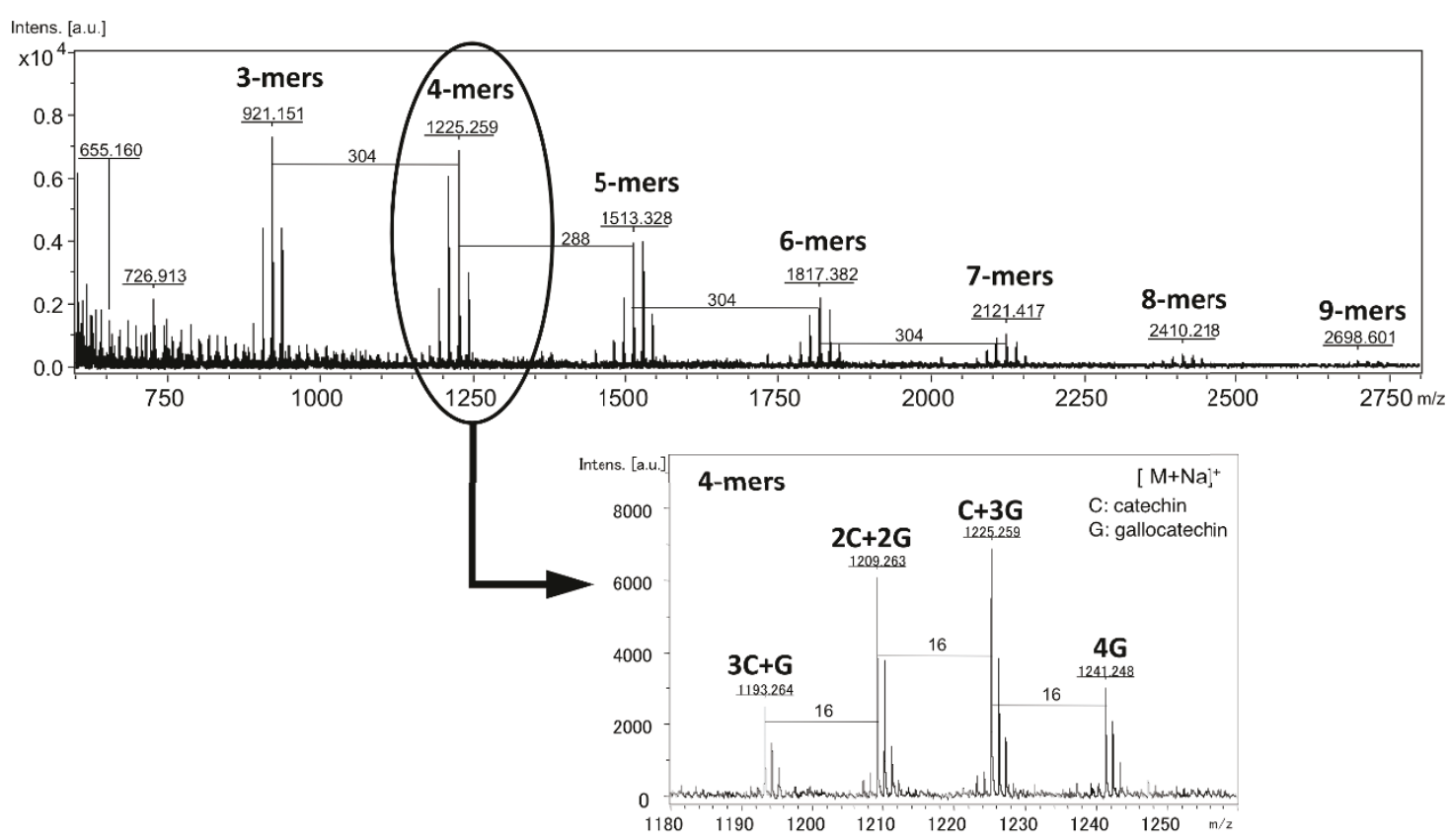

Figure 6 The positive reflection ion mode MALDI-TOF MS spectra of the lotus root polyphenols.

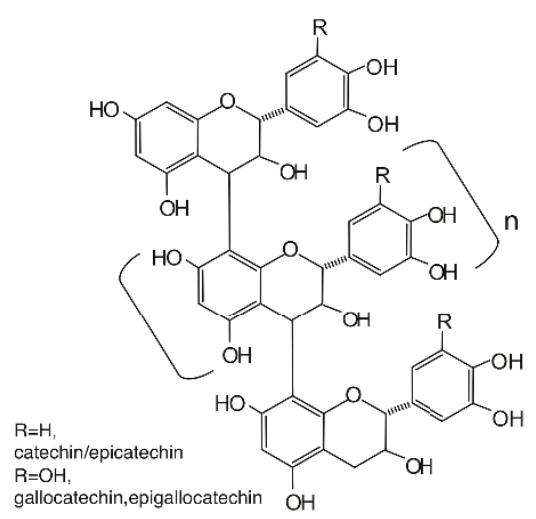

Figure 7 The putative structure of the condensed tannins in the polyphenolic lotus root extract. necessary to evaluate the metabolic fate of lotus root polyphenol and the precise mechanisms of its in vivo physiological properties.

\section{Conclusion}

Although further qualitative and quantitative analyses of lotus root polyphenols are necessary, the present results suggest that the ameliorative effect of dietary lotus root on hepatic steatosis in $d b / d b$ mice is attributable to the suppression of hepatic lipogenesis by the lotus root polyphenols. 
glutamic pyruvic transaminase; MALDI-TOF MS: matix-assisted laserdesorption ionization time-of-flight mass spectrometry; ME: malic enzyme; WAT: white adipose tissue; NAFLD: nonalcoholic fatty liver disease.

\section{Acknowledgements}

We thank Ichiko Matsumoto for her technical assistance. This work was supported by a research grant from the Japanese Ministry of Education, Culture, Sports, Science and Technology.

\section{Author details}

'Department of Applied Biochemistry and Food Science, Saga University, Saga 840-8502, Japan. 'Department of Biochemistry and Applied Biosciences, United Graduate School of Agricultural Sciences, Kagoshima University, Kagoshima 890-8580, Japan. Industrial Technology Center of Saga, Saga 849-0932, Japan

\section{Authors' contributions}

YT and KN made substantial contributions to the conception and design of the study, to performing the experiment, to the assembly, analysis and interpretation of the data and to drafting the manuscript. SK, KT, and TY participated in the experimental work and in the collection, assembly, analysis of the data. KK and TY contributed to planning the experiment and discussing the results. All authors read and approved the final manuscript.

\section{Competing interests}

The authors declare that they have no competing interests.

Received: 23 October 2011 Accepted: 9 November 2011 Published: 9 November 2011

\section{References}

1. Fan JG, Li F, Cai XB, Peng YD, Ao QH, Gao Y: Effects of nonalcoholic fatty liver disease on the development of metabolic disorders. J Gastroenterol Hepatol 2007, 22:1086-1091.

2. Harrison SA, Diehl AM: Fat and the liver-a molecular overview. Semin Gastrointest Dis 2002, 13:3-16.

3. Youssef W, McCullough AJ: Diabetes mellitus, obesity, and hepatic steatosis. Semin Gastrointest Dis 2002, 13:17-30.

4. Fong DG, Nehra V, Lindor KD, Buchman AL: Metabolic and nutritional considerations in nonalcoholic fatty liver. Hepatology 2000, 32:3-10.

5. Hummel KP, Dickie MM, Coleman DL: Diabetes, a new mutation in the mouse. Science 1966, 153:1127-1128.

6. Chen H, Charlat O, Tartaglia LA, Woolf EA, Weng X, Ellis SJ, Lakey ND, Culpepper J, Moore KJ, Breitbart RE, Duyk GM, Tepper RI, Morgenstern JP: Evidence that the diabetes gene encodes the leptin receptor: identification of a mutation in the leptin receptor gene in $\mathrm{db} / \mathrm{db}$ mice. Cell 1996, 84:491-495.

7. Lee GH, Proenca R, Montez JM, Carroll KM, Darvishzadah JG, Lee Gl, Freidman JM: Abnormal splicing of the leptin receptor in diabetic mice. Nature 1996, 379:632-635.

8. Nagao K, Yamano N, Shirouchi B, Inoue N, Murakami S, Sasaki T, Yanagita T: Effects of citrus auraptene (7-geranyloxycoumarin) on hepatic lipid metabolism in vitro and in vivo. J Agric Food Chem 2010, 58:9028-9032.

9. Nagao K, Inoue N, Inafuku M, Shirouchi B, Morooka T, Nomura S, Nagamori N, Yanagita T: Mukitake mushroom (Panellus serotinus) alleviates nonalcoholic fatty liver disease through the suppression of monocyte chemoattractant protein-1 production in $d b / d b$ mice. J Nutr Biochem 2010, 21:418-423.

10. Nagao K, Yanagita T: Bioactive lipids in metabolic syndrome. Prog Lipid Res 2008, 47:127-146.

11. Nagao K, Inoue N, Wang YM, Shirouchi B, Yanagita T: Dietary conjugated linoleic acid alleviates nonalcoholic fatty liver disease in Zucker (fa/fa) rats. J Nutr 2005, 135:9-13.

12. Scalbert A, Manach $C$, Morand C, Rémésy C, Jiménez L: Dietary polyphenols and the prevention of diseases. Crit Rev Food Sci Nutr 2005, 45:287-306.

13. Manach C, Mazur A, Scalbert A: Polyphenols and prevention of cardiovascular diseases. Curr Opin Lipidol 2005, 16:77-84.

14. Stoclet JC, Chataigneau T, Ndiaye M, Oak MH, El Bedoui J, Chataigneau M, Schini-Kerth VB: Vascular protection by dietary polyphenols. Eur $J$ Pharmacol 2004, 500:299-313.
15. Mukherjee PK, Mukherjee D, Maji AK, Rai S, Heinrich M: The sacred lotus (Nelumbo nucifera) - phytochemical and therapeutic profile. J Pharm Pharmaco 2009, 61:407-422.

16. Huang $B$, He J, Ban X, Zeng H, Yao X, Wang Y: Antioxidant activity of bovine and porcine meat treated with extracts from edible lotus (Nelumbo nucifera) rhizome knot and leaf. Meat Sci 2011, 87:46-53

17. Yan SL, Wang QZ, Peng GH: Determination of catechin in lotus rhizomes by high-performance liquid chromatography. Int J Food Sci Nutr 2009, 60:432-438.

18. Mukherjee PK, Saha K, Pal M, Saha BP: Effect of Nelumbo nucifera rhizome extract on blood sugar level in rats. J ethanoharmacol 1997, 58:207-213.

19. American Institute of Nutrition: Report of the American Institute of Nutrition ad hoc committee on standards for nutritional studies. J Nutr 1977, 107:1340-1348

20. Scalbert A, Williamson G: Dietary intake and bioavailability of polyphenols. J Nutr 2000, 30:2073-2085.

21. Folch J, Lees M, Sloane-Stanley GH: A simple method for the isolation and purification of total lipids from animal tissues. J Biol Chem 1957, 226:497-509.

22. Fletcher MJ: A colorimetric method for estimating serum triglycerides. Clin Chim Acta 1968, 22:393-397.

23. Sperry WM, Webb M: A revision of the Schoenheimer-Sperry method for cholesterol determination. J Biol Chem 1950, 187:97-106.

24. Kelley DS, Nelson GJ, Hunt JE: Effect of prior nutritional status on the activity of lipogenic enzymes in primary monolayer cultures of rat hepatocytes. Biochem J 1986, 235:87-90.

25. Ochoa S: Malic enzyme. In Methods in Enzymology. Volume 1. Edited by: Colowick SP, Kaplan NO. Academic Press: New York, NY; 1955:739-753.

26. Markwell MA, McGroarty EJ, Bieber LL, Tolbert NE: The subcellular distribution of carnitine acyltransferases in mammalian liver and kidney. J Biol Chem 1973, 248:3426-3432

27. Lowry OH, Rosebrough NJ, Farr AL, Randall RJ: Protein measurement with the Folin phenol reagent. J Biol Chem 1951, 193:265-275.

28. Takahata Y, Ohnishi-Kameyama M, Furuta S, Takahashi M, Suda I: Highly polymerized procyanidins in brown soybean seed coat with a high radical-scavanging activity. J Agric Food Chem 2001, 49:5843-5847.

29. Li XC, Joshi AS, ElSohly HN, Khan SI, Jacob MR, Zhang Z, Khan IA, Ferreira D, Walker LA, Broedel SE Jr, Raulli RE, Cihlar RL: Fatty acid synthase inhibitors from plants: isolation, structure elucidation, and SAR studies. J Nat Prod 2002, 65:1909-1914.

30. Ikeda I, Hamamoto R, Uzu K, Imaizumi K, Nagao K, Yanagita T, Suzuki Y, Kobayashi M, Kakuda T: Dietary gallate esters of tea catechins reduce deposition of visceral fat, hepatic triacylglycerol, and activities of hepatic enzymes related to fatty acid synthesis in rats. Biosci Biotechnol Biochem 2005, 69:1049-1053.

31. Su L, Deng Y, Zhang Y, Li C, Zhang R, Sun Y, Zhang K, Li J, Yao S: Protective effects of grape seed procyanidin extract against nickel sulfate-induced apoptosis and oxidative stress in rat testes. Toxicol Mech Methods 2011, 21:487-494.

32. Serrano J, Puupponen-Pimiä R, Dauer A, Aura AM, Saura-Calixto F: Tannins: current knowledge of food sources, intake, bioavailability and biological effects. Mol Nutr Food Res 2009, 53:S310-329.

33. Terra X, Montagut G, Bustos M, Llopiz N, Ardèvol A, Bladé C, FernándezLarrea J, Pujadas G, Salvadó J, Arola L, Blay M: Grape-seed procyanidins prevent low-grade inflammation by modulating cytokine expression in rats fed a high-fat diet. J Nutr Biochem 2009, 20:210-218.

34. Del Bas JM, Ricketts ML, Baiges I, Quesada H, Ardevol A, Salvadó MJ, Pujadas G, Blay M, Arola L, Bladé C, Moore DD, Fernandez-Larrea J: Dietary procyanidins lower triglyceride levels signaling through the nuclear receptor small heterodimer partner. Mol Nutr Food Res 2008, 52:1172-1181.

35. Del Bas JM, Ricketts ML, Vaqué M, Sala E, Quesada H, Ardevol A, Salvadó MJ, Blay M, Arola L, Moore DD, Pujadas G, Fernandez-Larrea J, Bladé C: Dietary procyanidins enhance transcriptional activity of bile acid-activated FXR in vitro and reduce triglyceridemia in vivo in a FXRdependent manner. Mol Nutr Food Res 2009, 53:805-814.

36. Bladé C, Arola L, Salvadó MJ: Hypolipidemic effects of proanthocyanidins and their underlying biochemical and molecular mechanisms. Mol Nutr Food Res 2010, 54:37-59.

37. Deprez S, Mila I, Huneau JF, Tome D, Scalbert A: Transport of proanthocyanidin dimer, trimer, and polymer across monolayers of 
human intestinal epithelial Caco-2 cells. Antioxid Redox Signal 2001, 3:957-967.

38. Holt RR, Lazarus SA, Sullards MC, Zhu QY, Schramm DD, Hammerstone JF, Fraga CG, Schmitz HH, Keen CL: Procyanidin dimer B2 [epicatechin(4beta-8)-epicatechin] in human plasma after the consumption of a flavanol-rich cocoa. Am J Clin Nutr 2002, 76:798-804.

39. Gonthier MP, Donovan JL, Texier O, Felgines C, Remesy C, Scalbert A Metabolism of dietary procyanidins in rats. Free Radic Biol Med 2003, 35:837-844.

40. Serra A, Macià A, Romero MP, Valls J, Bladé C, Arola L, Motilva MJ: Bioavailability of procyanidin dimers and trimers and matrix food effects in in vitro and in vivo models. Br J Nutr 2010, 103:944-952.

doi:10.1186/1476-511X-10-202

Cite this article as: Tsuruta et al:: Polyphenolic extract of lotus root (edible rhizome of Nelumbo nucifera) alleviates hepatic steatosis in obese diabetic $d b / d b$ mice. Lipids in Health and Disease 2011 10:202.

\section{Submit your next manuscript to BioMed Central} and take full advantage of:

- Convenient online submission

- Thorough peer review

- No space constraints or color figure charges

- Immediate publication on acceptance

- Inclusion in PubMed, CAS, Scopus and Google Scholar

- Research which is freely available for redistribution

Submit your manuscript at www.biomedcentral.com/submit 